\title{
Overexpression of Specific CD44 Isoforms Is Associated with Aggressive Cell Features in Acquired Endocrine Resistance
}

\author{
Rebecca Bellerby', Chris Smith', Sue Kyme', Julia Gee', Ursula Günthert' ${ }^{2}$ Andy Green ${ }^{3}$, \\ Emad Rakha ${ }^{3}$, Peter Barrett-Lee ${ }^{4}$ and Stephen Hiscox ${ }^{1 *}$ \\ 'School of Pharmacy and Pharmaceutical Sciences, Cardiff University, Cardiff, UK, ${ }^{2}$ Institute of Pathology, University \\ Hospital of Basel, Basel, Switzerland, ${ }^{3}$ Faculty of Medicine and Health Sciences, University of Nottingham, Nottingham, UK, \\ ${ }^{4}$ Velindre Cancer Centre, Cardiff, UK
}

\section{OPEN ACCESS}

Edited by:

Rosemary O'Connor, University College Cork (UCC),

Ireland

Reviewed by:

Leonard Girnita,

Karolinska Institutet, Sweden

Xiaoxia Zhu,

University of Miami, USA

*Correspondence:

Stephen Hiscox

hiscoxse1@cf.ac.uk

Specialty section:

This article was submitted

to Cancer Endocrinology,

a section of the journal

Frontiers in Oncology

Received: 17 March 2016

Accepted: 27 May 2016

Published: 20 June 2016

Citation:

Bellerby R, Smith C, Kyme S, Gee J,

Günthert U, Green A, Rakha E,

Barrett-Lee P and Hiscox S (2016)

Overexpression of Specific CD44

Isoforms is Associated with

Aggressive Cell Features in

Acquired Endocrine Resistance.

Front. Oncol. 6:145.

doi: 10.3389/fonc.2016.00145
While endocrine therapy is the mainstay of ER+ breast cancer, the clinical effectiveness of these agents is limited by the phenomenon of acquired resistance that is associated with disease relapse and poor prognosis. Our previous studies revealed that acquired resistance is accompanied by a gain in cellular invasion and migration and also that CD44 family proteins are overexpressed in the resistant phenotype. Given the association of CD44 with tumor progression, we hypothesized that its overexpression may act to promote the aggressive behavior of endocrine-resistant breast cancers. Here, we have investigated further the role of two specific CD44 isoforms, CD44v3 and CD44v6, in the endocrine-resistant phenotype. Our data revealed that overexpression of CD44v6, but not CD44V3, in endocrine-sensitive MCF-7 cells resulted in a gain in EGFR signaling, enhanced their endogenous invasive capacity, and attenuated their response to endocrine treatment. Suppression of CD44v6 in endocrine-resistant cell models was associated with a reduction in their invasive capacity. Our data suggest that upregulation of CD44v6 in acquired resistant breast cancer may contribute to a gain in the aggressive phenotype of these cells and loss of endocrine response through transactivation of the EGFR pathway. Future therapeutic targeting of CD44v6 may prove to be an effective strategy alongside EGFR-targeted agents in delaying/preventing acquired resistance in breast cancer.

Keywords: CD44, breast cancer, endocrine resistance, invasion

\section{INTRODUCTION}

Over two-thirds of breast cancers express the estrogen receptor and are, likely to respond to endocrine therapies exemplified by tamoxifen $(1,2)$. However, despite the undoubted improvements brought by such treatments, acquired resistance to these agents remains a significant problem with resistant tumors frequently recurring at distant sites (3). Increasingly, evidence suggests that a gain in aggressive, metastatic cell functions accompanies acquisition of resistance (4-7) although the mechanisms underlying this are unclear. Thus, a greater understanding of the molecular pathways associated with resistance is needed in order to highlight better therapeutic opportunities. To this end, we have previously reported that acquired tamoxifen resistance in 
breast cancer is accompanied by the overexpression of the CD44 transmembrane receptor protein that appears to contribute to their aggressive phenotype through modulation of growth factor receptor signaling.

A challenge to developing therapies against CD44lies in the fact that CD44 represents a large family of variant isoforms expressed through alternative splicing of the CD44 gene and controversy exists as to which isoforms are tumor-protective and which may act to promote tumor progression $(8,9)$. However, the majority of studies appear to have focused on CD44v3 and CD44v6 and their role as promoters of tumor migration, invasion, and spread (10-13). CD44v6 is specifically implicated in the tumorigenesis and migration of tumor cells during metastasis $(14,15)$ while overexpression of CD44v6 is suggested to predict overall survival (OS) and disease-free survival (DFS) in breast and other cancers (16-18). A number of studies also support an association between CD44v3 and invasion (10) and metastasis (19, 20). Interestingly, in many of these cases, it is the co-expression of CD44 isoforms alongside other growth factor receptors that confers a poor prognostic signature.

While our previous study looked at global CD44 expression, identifying specific CD44 variants that may play a role in drug resistance represents an important goal with respect to identifying specific elements that may represent future therapeutic opportunities. In this study, we provide data supporting the hypothesis that the CD44v6 rather than CD44v3 acts to limit endocrine response and promote tumor progression through EGFR transactivation in breast cancer cells. Importantly, our translational studies further suggest that CD44v6 and EGFR co-expression may represent an important prognostic marker for $\mathrm{ER}+$ breast cancers.

\section{MATERIALS AND METHODS}

\section{Cell Culture}

Endocrine responsive MCF-7 cells were maintained in phenolred free RPMI with L-glutamine $(200 \mathrm{mM})$ containing $5 \%$ (v/v) fetal calf serum and antibiotics [penicillin (10 IU/ml), streptomycin $(10 \mu \mathrm{g} / \mathrm{ml})$, and fungizone $(2.5 \mu \mathrm{g} / \mathrm{ml})]$. Tamoxifenresistant (Tam-R) and fulvestrant-resistant (Fas-R) cells $(4,7)$ were cultured in phenol-red free RPMI containing 5\% (v/v) charcoal-stripped steroid depleted fetal calf serum, antibiotics as above and supplemented with 4-hydroxy tamoxifen (100 mM) or fulvestrant $(100 \mathrm{mM})$, respectively. Antibodies were used that recognized CD44 Std (Clone 156-3C11; Fisher Scientific), antiCD44v3 (Clone VFF-327) and anti-CD44v6 (Clone 2F10) (both R\&D Systems), and RHAMM (Abcam). All other antibodies were purchased from Cell Signaling Technologies. All other reagents were from Sigma Ltd. (Dorset, UK), unless otherwise stated.

\section{Microarray Analysis}

Triplicate RNA samples from MCF-7, Tam-R, and Fas-R cells were microarrayed using Affymetrix Human Genome U133A gene chips with subsequent median normalization across all datasets and log transformation using Genesifter. Heatmap profiles and $\log 2$ intensity plots were generated to visualize gene expression changes across all cell models. The genes analyzed by microarray were as follows: CD44, HMMR (the gene corresponding to the RHAMM protein), stabilin 2 (STAB-2), lymphatic vessel endothelial receptor 1 (LYVE-1), toll-like receptor 4 (TL4), intracellular adhesion molecule-1 (ICAM-1), and versican (VCAN). Statistical analysis of probe expression between cells was performed using ANOVA with Tukey post hoc analysis.

\section{RT-PCR}

mRNA was isolated from MCF-7, Tam-R, and Fas- $\mathrm{R}$ cells and reverse-transcribed to cDNA using primers corresponding to the standard form of CD44 (sF: 5'GACACATATTGG CTTCAATGCTTCAGC3'; sR: GATGCCAAGATGATCAGCCA TTCTGGAAT3'), CD44 variant 3 (sF:5' AGTCACAGACCTGC CCAATGCCTTT3'; sR: 5'GGTGTCTGTCTCTTTCATCTTCA TTTTTCTTCATTT3'), variant 6 (sF: 5' CAACGGAAGAAAC AGCTACC3'; sR: 5'CCTGTTGTCGAATGGGAGTC3'), and $\beta$-actin (sF: 5'GGAGAATGATCTTGATCTT3' sR 5'CCTTCCT TGGGCATGGAGTCCT3'). All PCRs were performed in a semi-quantitative manner using 27-30 cycles so that products were in a linear range of amplification. PCR products were separated and visualized on a $1 \%$ agarose gel using ethidium bromide and photographed (representative images are shown from a minimum of three separate experiments).

\section{Cell Lysis and Western Blotting}

Log phase cultures were lysed in Triton X100 lysis buffer containing protease inhibitors. Clarified supernatants were boiled in sample buffer and equal amounts of proteins and resolved by $8 \%$ SDS-PAGE. Separated proteins were immobilized on nitrocellulose membranes and probed with antibodies against CD44 Std, CD44v6, CD44v3, RHAMM, and the activated forms of EGFR (Y1068), ErbB2 (Y1248), Met (Y1234/1235), FAK (Y397), MAPK (T202/Y204), AKT (S473), Src (Y416), and GAPDH. Bound primary antibodies were detected by HRP-conjugated secondary anti-mouse or anti-rabbit IgG (Fisher Scientific, UK) and subsequent chemiluminescence analysis. Representative blots are shown from a minimum of three separate experiments.

\section{Immunocytochemistry}

Log-phase cultures of MCF-7, Tam-R, and Fas-R cells were fixed with $2.5 \%$ phenol formal saline and stained with primary antibodies. Antibody detection was performed with Dako mouse EnVision (peroxidase-labeled polymer) for $30 \mathrm{~min}$ and DAB chromogen, counterstaining with $1 \%$ methyl green. Photographs were taken of cells at $\times 40$ magnification. Plasma membrane and cytoplasm percentage positivity were assessed to derive a total $H$-score value for each cell line.

\section{Immunohistochemical Analysis of CD44v6 Expression in Clinical Breast Cancer}

Tumor tissue was available from patients with histologically proven breast cancer that presented for surgery at Nottingham City Hospital between 1984 and 1987. This series comprised part of an historical breast cancer collection with approval for use without further patient consent [approved ethics application 
C108030; Nottingham Research Ethics Committee (21)]. All patients received systemic tamoxifen therapy for locally advanced primary carcinoma $(>5 \mathrm{~cm})$ and the duration of anti-hormonal response and survival from the initiation of therapy monitored for each patient by follow-up after surgery. No patient had previously received any form of adjuvant endocrine or cytotoxic therapy; the median patient age was 54 years (age range 25-77 years). Survival and duration of anti-hormone response were measured from commencement of anti-hormone to death or progression on therapy, respectively. All patient-related information was anonymized and de-identified prior to analysis and the EGFR status of these tumors was previously reported (22). Paraffin-embedded tissue sections were subject to antigen retrieval by microwaving for $30 \mathrm{~min}$ in $0.1 \mathrm{M}$ citrate buffer ( $\mathrm{pH} \mathrm{6)}$. Following elimination of endogenous peroxide, sections were then blocked with $10 \%$ normal human serum in PBS for $10 \mathrm{~min}$. Immunostaining was then performed using CD44v3 (1/80) and CD44v6 (1/40) antibodies for $2 \mathrm{~h}$ and antibody detection was performed with Dako mouse EnVision (peroxidase-labeled polymer) for $90 \mathrm{~min}$ and $\mathrm{DAB}$ chromogen for $10 \mathrm{~min}$, counterstaining with $1 \%$ methyl green for $15 \mathrm{~min}$. Negative controls were incubated with mouse isotype-specific control IgG (Dako). All sections were assessed simultaneously by two observers blinded to the clinical data using a dual-viewing light microscope ( $\times 40$ magnification). Matched control slides were checked for non-specific binding before assessment of staining intensity. The data were then used to construct a CD44v6 $\mathrm{H}$-score for each tumor specimen as described below. Statistical analysis [Log Rank (Mantel-Cox)] was used to investigate relationship between CD44v6 and EGFR and clinicopathological parameters using SPSS version 20. Kaplan-Meier survival curves were plotted with a log-rank test to analyze the differences between curves. The relative influence of CD44v6 and EGFR on survival was examined using multivariate analysis according to the non-parametric hazards model of Cox. Significance was set at $P<0.05$.

\section{Evaluation of Immunohistochemical Staining}

Staining intensity was evaluated using the $H$-score as follows: for each sample, six fields of view were investigated and allocated a value between 0 and 3 dependent on staining intensity ( $0=$ negative staining, $3=$ strong staining). A total $H$-score value was calculated using the formula: $(\%$ at 0$) \times 0+(\%$ at 1$) \times 1+(\%$ at $2) \times 2+(\%$ at 3$) \times 3$ to give an overall score ranging between 0 and 300 . Differences between groups were statistically compared using the Student's $t$-test. Representative images are shown from a minimum of three separate experiments.

\section{Analysis of Cell Migration}

A total of $3 \times 10^{4}$ cells were seeded into the top chambers of 24-well transwell plates (BD Biosciences, $8.0 \mu \mathrm{m}$ pore size coated with $10 \mu \mathrm{g} / \mathrm{ml}$ fibronectin) with complete media added to the bottom chamber. After $24 \mathrm{~h}$ of culture, migratory cells (cells that had moved to the underside of the membrane) were fixed with $3.7 \%$ paraformaldehyde, stained with $0.5 \%$ crystal violet, and counted at $\times 40$ magnification under a light microscope.
Cell migration was quantified as the mean number of cells observed in each of five random fields of view per sample, each performed in duplicate over three independent experiments and then normalized to the untreated controls (i.e., expressed as a percentage of the cells migrating in the control samples). Differences between groups were statistically compared using the Student's $t$-test.

\section{Boyden Chamber Invasion Assay}

A total of $3 \times 10^{4}$ cells were seeded onto Matrigel-coated $(9.6 \mathrm{mg} /$ $\mathrm{ml})$ transwell chambers $(8 \mu \mathrm{m}$ pore size) with complete media in the bottom chamber. After $72 \mathrm{~h}$ of culture, the membranes from each transwell insert were removed to allow cells that had invaded through the Matrigel layer to the underside of the membrane to be fixed with $3.7 \%$ paraformaldehyde prior to mounting on microscope slides using DAPI-containing vector shield. Cell nuclei were counted at $\times 60$ magnification using a fluorescent microscope. Cell invasion was quantified as above by counting the mean number of cells observed in each of five random fields of view per sample, each performed in duplicate and normalizing to controls (untreated samples). Differences between groups were statistically compared using the Student's $t$-test.

\section{Coulter Counter Growth Assay}

Cell proliferation was determined using the Coulter counter growth assay. Briefly, cells were seeded into 24 -well plates at $1.5 \times 10^{6}$ cells/plate and left to adhere for $24 \mathrm{~h}$. Subsequently, fresh medium containing treatments as described were added and cells were cultured for a further 5 days. Media were then removed from the wells and replaced with $1 \mathrm{ml} /$ well trypsin and returned to the incubator until cells were in suspension. Trypsin $(4 \mathrm{ml} /$ well $)$ was added using a sterile syringe and this solution was added to $6 \mathrm{ml}$ Isoton. The $11 \mathrm{ml}$ Isoton cell suspension was counted twice on a Coulter counter (CoulterTM Multisizer II, UK) according to manufacturer's instructions. The average count was multiplied by 20 to calculate cells/well. Differences between groups were statistically compared using the Student's $t$-test.

\section{siRNA-Mediated Gene Suppression in Endocrine-Resistant Cells}

siRNA knockdown of CD44 (all forms), CD44v6, and RHAMM was performed in Tam-R and Fas- $\mathrm{R}$ cells as follows. Briefly, logphase Tam-R and Fas- $R$ cells were inculbated with $100 \mathrm{nM}$ siRNA/ lipid mixture as per the manufacturer's protocol (Dharmacon Ltd.) for $48 \mathrm{~h}$. Suppression of gene and protein expression was confirmed using PCR and Western blotting. After gene suppression, cells were harvested and used in the assays described above. Control experiments used either non-targeting (NT) siRNA or transfection lipid only.

\section{Transient Transfection of Endocrine-Sensitive MCF-7 Cells with CD44v3 and CD44v6}

Plasmid constructs containing cDNA corresponding to CD44v3 and CD44v6 isoforms (in a pPGK-T7/2 vector) were provided by Ursula Günthert, Basel University. These constructs 
were introduced into MCF-7 cells as follows. Briefly, cells at $50 \%$ confluency were incubated with transfection lipid alone (FuGENE 6, Promega, UK) or with transfection lipid plus the DNA plasmid construct (100 ng/well at 3:1 lipid:DNA ratio) in culture medium for $48 \mathrm{~h}$ after which cells were harvested and used in the assays described.

\section{RESULTS}

\section{CD44v3 and CD44v6 Are Overexpressed in Acquired Tamoxifen- and Fulvestrant-Resistant Breast Cancer Cells}

An initial interrogation of our in-house microarray database was performed to identify members of the wider hyaladherin family, as well as CD44 itself, that may be deregulated in acquired resistance compared to their drug-sensitive counterparts (Figure 1A). These data pointed to an upregulation of both CD44 and receptor for HA-mediated motility (HMMR/RHAMM) in Tam-R and Fas-R models compared to MCF-7 cells, while expression of other hyaladherin members, LYVE-1, TL4, STAB-2, ICAM1 , and VCAN were suppressed. As the microarray probe sets could not differentiate between CD44 isoforms, RT-PCR was performed to explore whether specific CD44 isoforms (specifically CD44v3 and CD44v6) were altered in addition to global CD44 expression. RT-PCR confirmed the microarray data showing upregulation of global CD44 transcripts and further revealed elevated expression of CD44v3 and CD44v6 isoforms in the resistant models (Figure 1B). Elevated levels of CD44, $\mathrm{v} 3$, and v6 isoforms were subsequently confirmed at the protein level by Western blotting that revealed higher levels of CD44 Std (80 kDa), CD44v3 (85 kDa), and CD44v6 (85-200 kDa) in Tam-R and Fas-R cells versus their MCF-7 counterparts (Figure 1C). Immunocytochemical staining of CD44 Std and CD44v6 isoforms revealed predominant cell surface staining in contrast to CD44v3 proteins that revealed intense cytoplasmic staining (Figure 1D). Quantitation of staining by $\mathrm{H}$-score revealed a CD44 distribution profile across the cell lines largely reflecting the Western data, with overexpression of CD44 and its variants in the resistant cells compared to their endocrine-sensitive counterparts. Cytoplasmic expression appeared similar although CD44v3 levels appeared only modestly elevated in Tam-R cells in contrast to the Western data (Figure 1E).

\section{Inhibition of CD44 Suppresses the Aggressive Phenotype of Endocrine-Resistant Breast Cancer Cells}

Our previous research has shown that endocrine resistance is accompanied by aggressive cellular behavior (23) and confirmed in this study (Figure 2A). To begin to understand the contribution of CD44 variants to cellular phenotype in the context of acquired

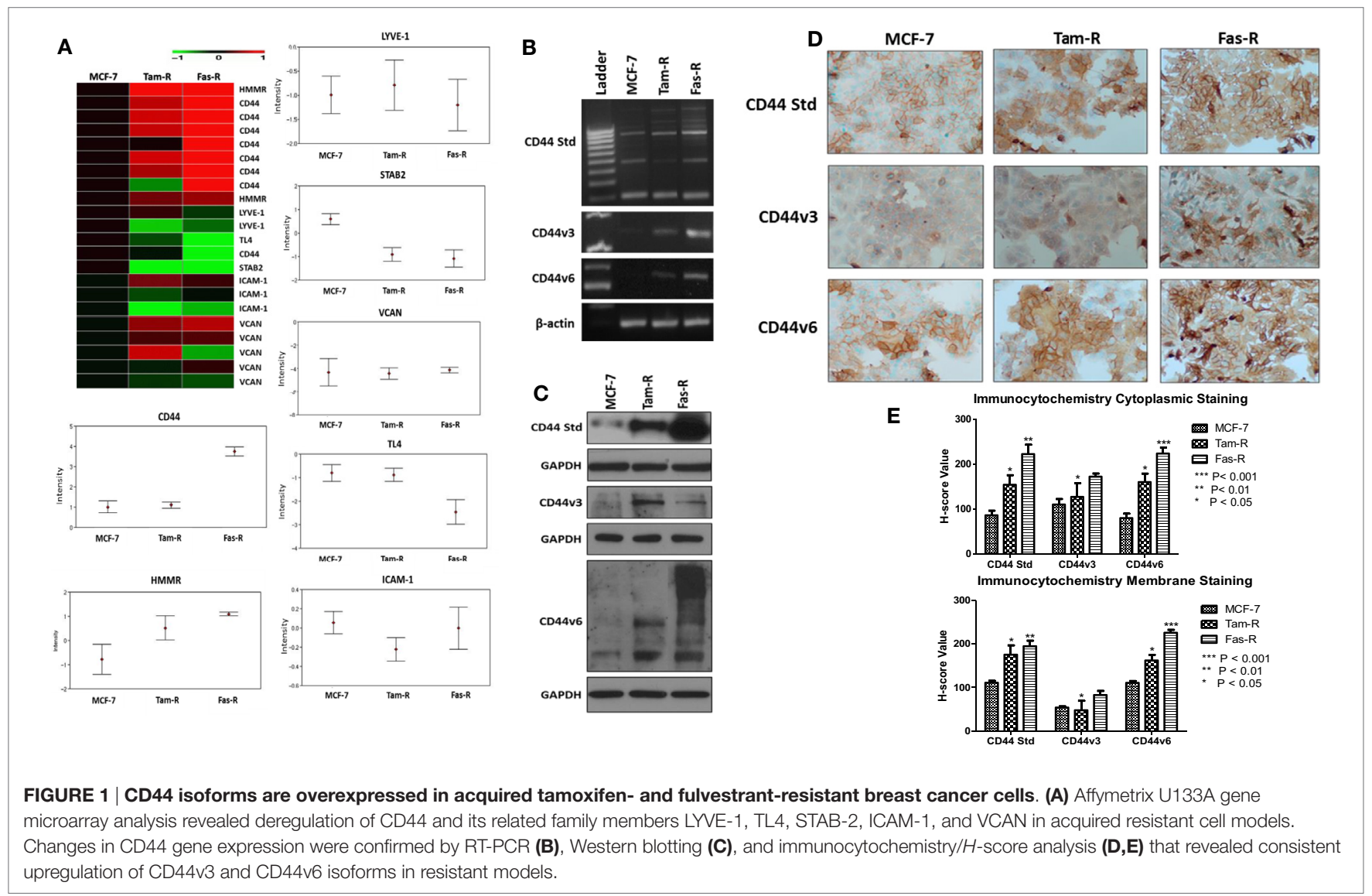




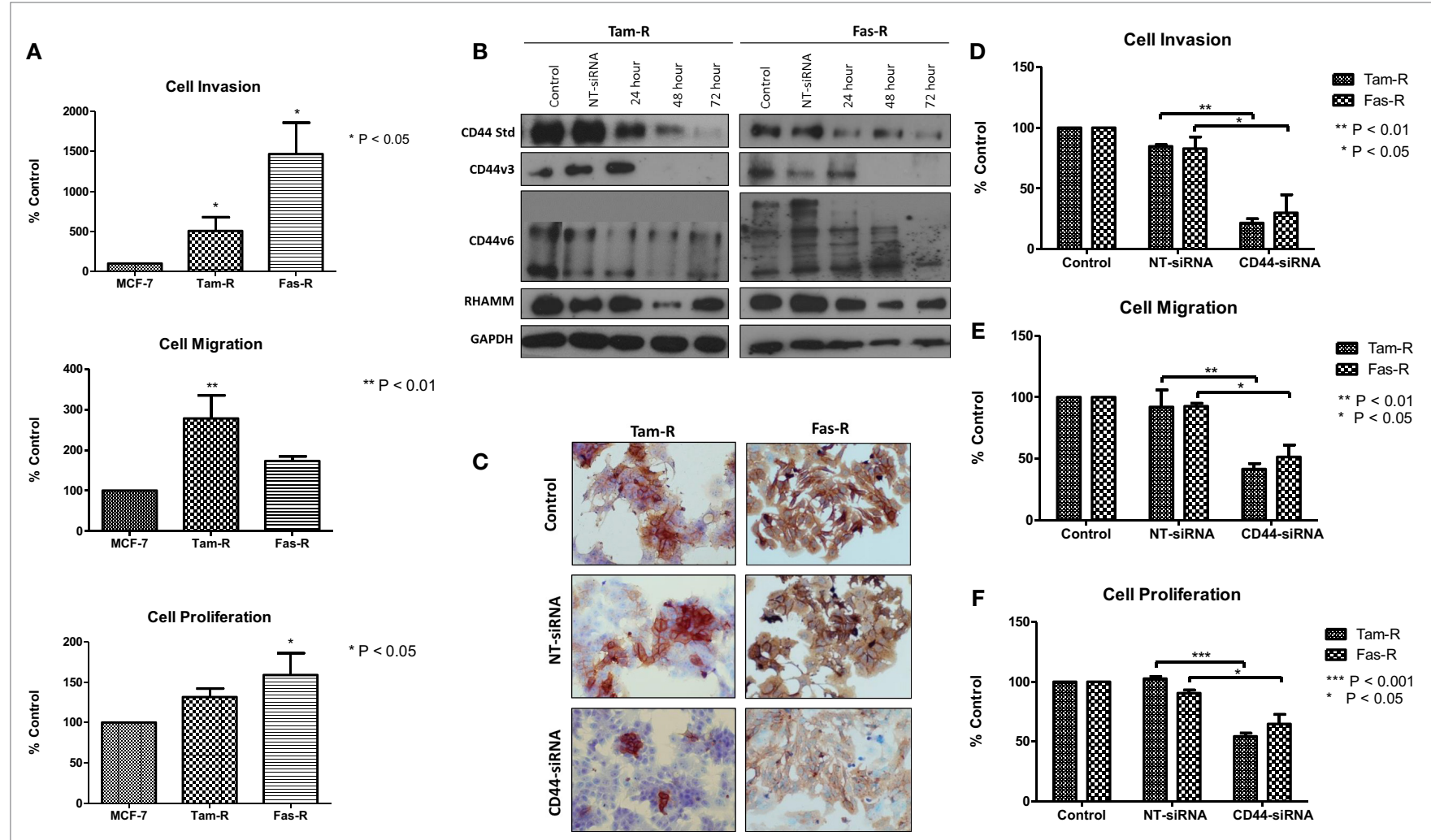

FIGURE 2 | siRNA-mediated CD44 suppression reduces the aggressive behavior of endocrine-resistant breast cancer cell models. (A) Tam-R and Fas-R cells display enhanced migratory, invasive, and proliferative capacity compared to MCF-7 cells. (B) Western blotting demonstrated that treatment of Tam-R and Fas-R cells with CD44-siRNA resulted in suppression of CD44s, CD44v3, and CD44v6 isoforms and global CD44 loss was confirmed by immunocytochemistry (C). Suppression of CD44 expression subsequently resulted in loss of invasive (D), migratory (E), and proliferative responses (F) in Tam-R and Fas-R cells.

endocrine resistance, we first suppressed all forms of endogenous CD44 in Tam-R and Fas-R cells using siRNA (Figures 2B,C). This resulted in a reduction in the intrinsic migratory, proliferative, and invasive nature of both resistant cell lines (Figures 2D-F).

\section{CD44-siRNA Reduces EGFR and Met Pathway Activity in Tam-R and Fas-R Cells, Respectively}

Growth factor receptor pathway activity is suggested to play an important role in resistance with previous reports implicating the EGFR/HER2 $(3,24)$ and c-Met $(7)$ pathways in acquired tamoxifen and fulvestrant resistance respectively where they may contribute to an enhanced migratory phenotype. Since CD44 can act as a co-receptor for receptor tyrosine kinases (25-27) we investigated whether signaling through these receptors was affected in the absence of CD44. Western blotting revealed that, following suppression of CD44 expression by siRNA, there was a reduction of endogenous EGFR and associated signaling pathway activity in Tam-R cells (Figure 3A). While no effects were seen on EGFR signaling in Fas-R cells, suppression of CD44 in these cells reduced the activity of the Met receptor (Figure 3) previously implicated in Fas-R cell migratory responses (7).
Accompanying this decrease was a suppression of MAPK and AKT in both cell lines; no changes were observed in total levels of these proteins (Figure 3).

\section{RHAMM Does Not Contribute to the Aggressive Phenotype of}

\section{Endocrine-Resistant Breast Cancer Cells}

In light of reports that suggest a role for HMMR (RHAMM) in tumor progression $(28,29)$, we investigated whether RHAMM was contributory toward the endocrine-resistant phenotype of Tam- $\mathrm{R}$ and Fas-R cells. Our previous affymetrix data suggested upregulation of RHAMM gene expression in both endocrine-resistant cell models; however, confirmation of RHAMM protein expression by Western blotting revealed a similar level of expression across our cell models (Figure 4A). Immunocytochemistry confirmed these findings and showed slightly reduced RHAMM expression in both endocrine-resistant cells compared to MCF-7 cells and revealed predominant cytoplasmic expression of RHAMM across our cell models (Figure 4B). RHAMM suppression by siRNA did not modulate the expression of CD44 proteins (Figure 4C) and did not alter the aggressive nature of Fas-R cells; interestingly, a reduced level of proliferation was observed in Tam- $\mathrm{R}$ cells 

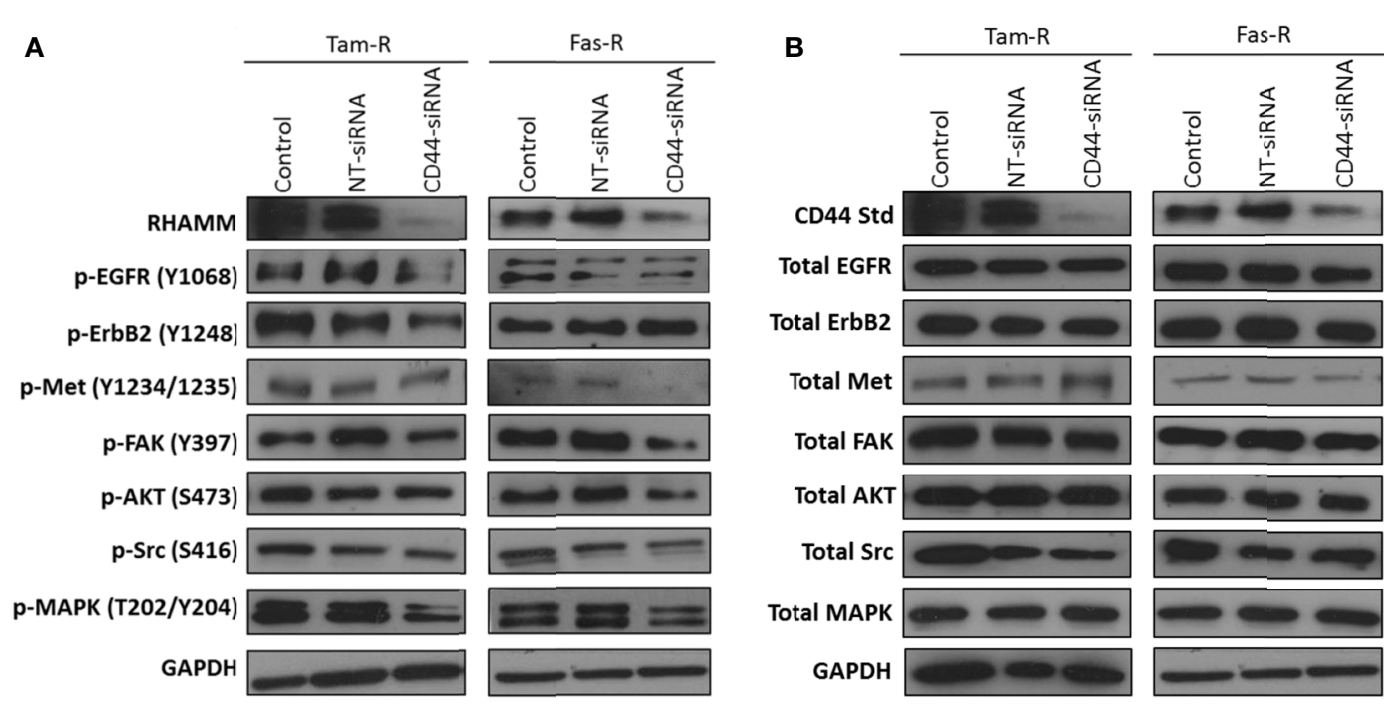

FIGURE 3 | Inhibition of CD44 expression suppresses endogenous growth factor pathway activity in Tam-R and Fas-R cells. Western blotting analysis was used to determine the effects of CD44 suppression on signaling activity in Tam-R and Fas-R cells. (A) CD44 suppression reduced EGFR, ErbB2, and MAPK phosphorylation in Tam-R cells and reduced Met, AKT, and MAPK phosphorylation in Fas-R cells. (B) No change in total protein levels was observed.

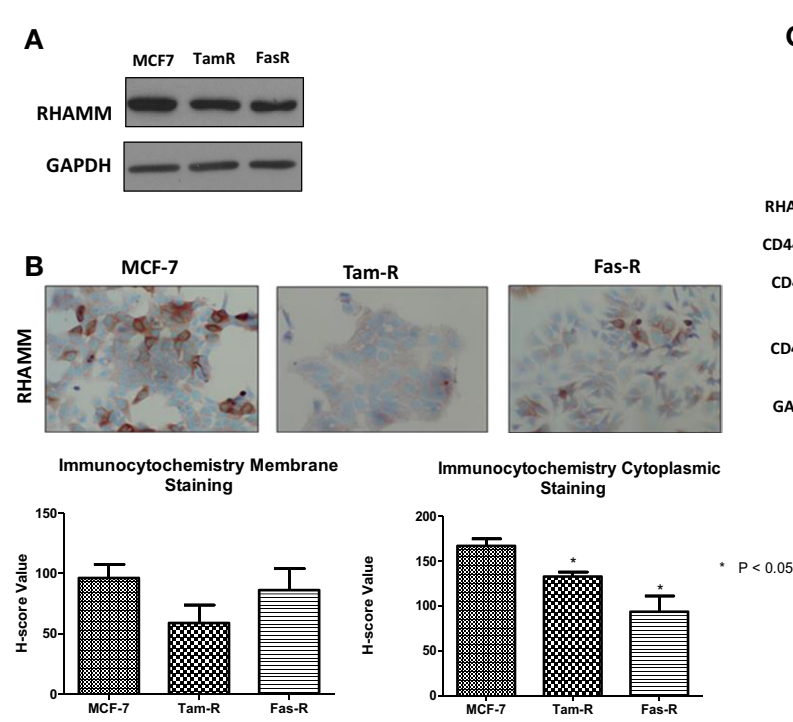

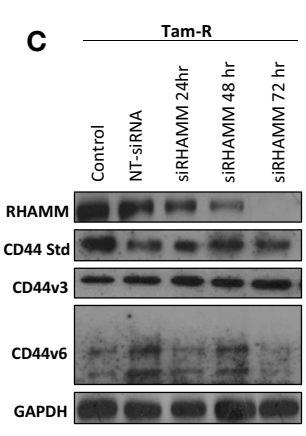
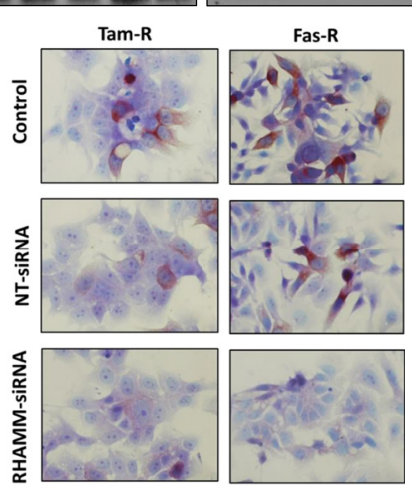

Fas-R
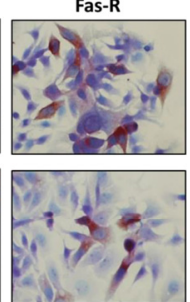
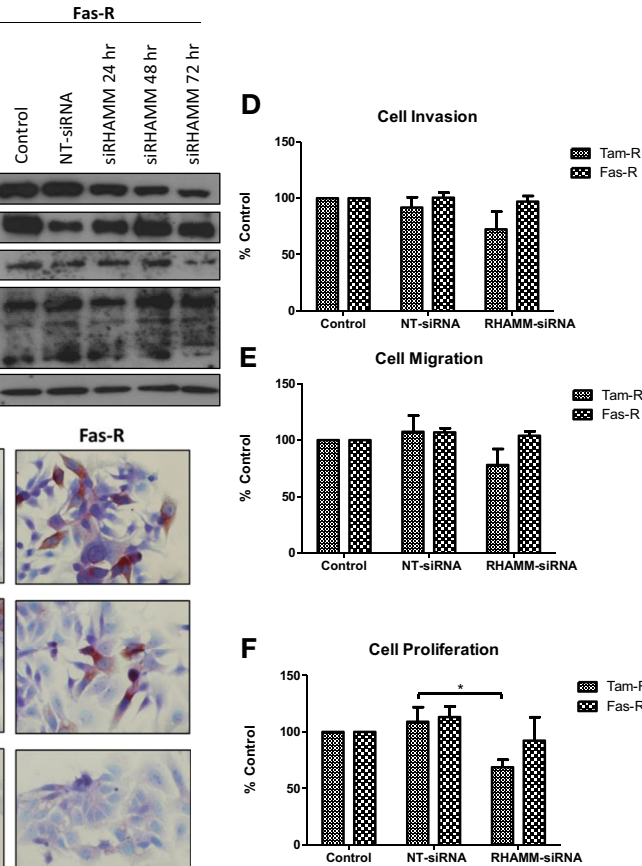

FIGURE 4 | Inhibition of RHAMM expression does not alter the aggressive behavior of endocrine-resistant breast cancer cells. (A) Western blotting revealed a similar level of RHAMM protein expression across MCF-7, Tam-R, and Fas-R cells, which was confirmed by immunocytochemistry and $H$-score analysis. (B). Suppression of RHAMM by siRNA (C), confirmed with immunocytochemical staining and Western blotting, did not alter CD44 variant isoform expression. RHAMM suppression did not alter the invasive (D) or migratory (E) capacity of Tam- $R$ and Fas- $R$ cells although some suppression of Tam- $R$ proliferation was observed in the absence of RHAMM (F)

after RHAMM knockdown (Figures 4D-F). Western blotting of cells following suppression of RHAMM by siRNA revealed that removal of RHAMM did not affect intrinsic receptor tyrosine kinase signaling in Tam-R cells (Figure 5); a similar case was seen for Fas-R cells, although a small reduction was observed in Met and FAK activity. 

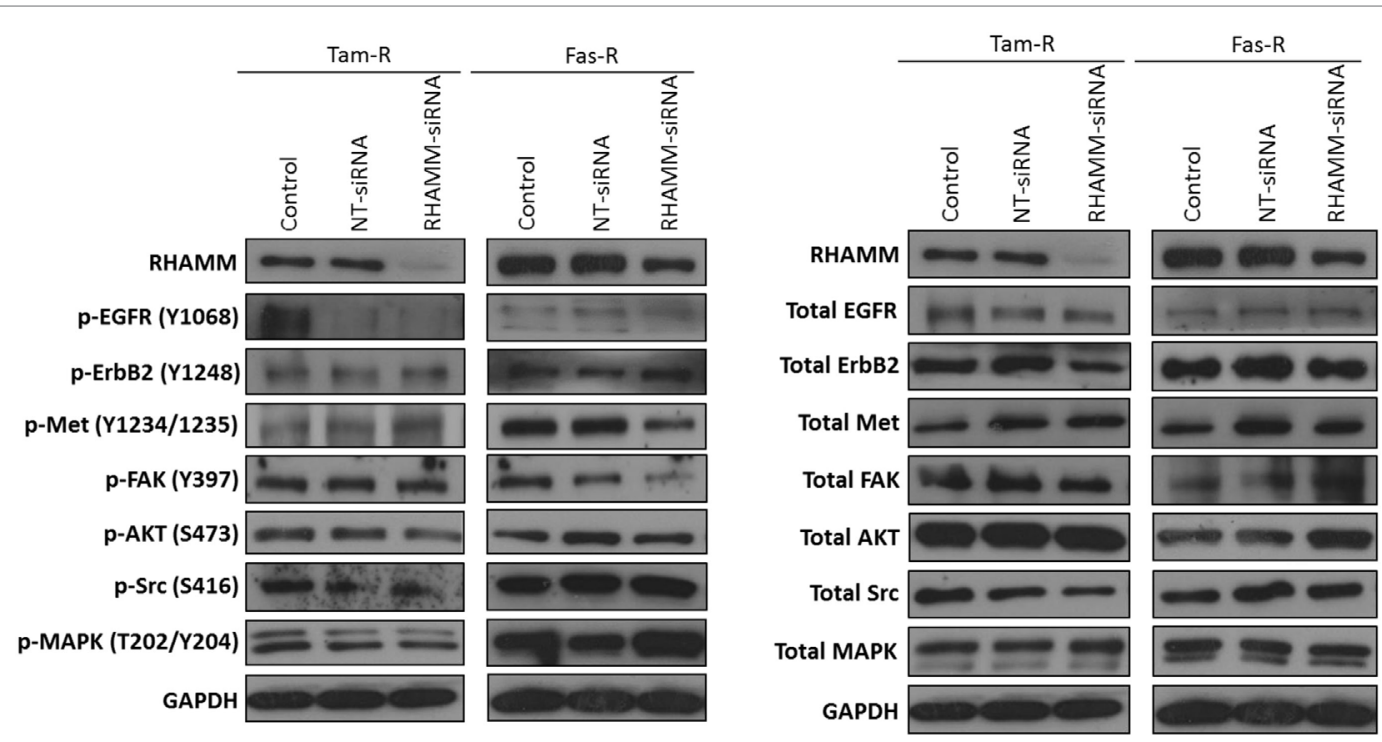

FIGURE 5 | Effects of RHAMM suppression on pathway signaling. Western blotting of cells following treatment with RHAMM siRNA revealed that RHAMM suppression did not significantly alter receptor tyrosine kinase and associated pathway signaling in Tam-R cells; however, Fas-R cells showed modest reductions in Met and FAK activity. No change in total protein levels was observed in the absence of RHAMM.

\section{Overexpression of CD44v6, but not CD44v3, in MCF-7 Cells Promotes Cellular Invasion and Attenuates Endocrine Response}

Our siRNA data suggest that CD44 per se plays an important role in mediating the aggressive phenotype of acquired endocrineresistant breast cancer cells. However, many CD44 isoforms exist and it is not clear regarding which of these are the dominant contributors in the context of endocrine resistance. To further validate a role for CD44 in the development of an aggressive breast cancer cell phenotype and to begin to explore any differential contribution of CD44 isoforms, we overexpressed CD44v3 and CD44v6, two specific isoforms we have shown to be upregulated in Tam-R and Fas-R cells, separately in MCF-7 cells and assessed any changes to cellular phenotype. Transfection of MCF-7 cells with CD44v3 or CD44v6 resulted in upregulated expression of these isoforms without affecting the expression of other CD44 variants (Figure 6A). Overexpression of CD44v6 resulted in a significant increase in cellular invasion compared to untreated MCF-7 cells; however, this effect was not observed in MCF-7 cells overexpressing CD44v3 (Figure 6B). Interestingly, $\mathrm{CD} 44 \mathrm{v} 3$ appeared to also reduce the proliferative and migratory capacity of these cells (Figures 6C,D). Our previous findings suggested that CD44 expression may limit endocrine response in breast cancer cells (23). To investigate this further, specifically in the context of CD44 isoforms, the growth of CD44 isoformtransfected cells was determined in the presence of tamoxifen and fulvestrant. Our data revealed that while CD44v3 overexpression in MCF-7 cells did not significantly alter their response to these agents, overexpression of CD44v6 attenuated the ability of MCF-7 cells to respond to fulvestrant resulting in enhanced proliferative capacity of these cells (Figure 6E). No changes in CD44 variant expression were observed in response to endocrine treatment (data not shown).

\section{Overexpression of CD44v6 Promotes EGFR Signaling in MCF-7 Cells}

Given that our data demonstrated suppression of CD44 inhibited the endogenous activity of the EGFR and Met pathways in our endocrine-resistant cells, we explored the hypothesis that overexpression of CD44 variants in MCF-7 cells might augment growth factor pathway activity. Overexpression of CD44v3 resulted in a modest reduction in ErbB receptor phosphorylation and an increase in AKT and Src activity (Figure 7A). By contrast, MCF-7 cells overexpressing CD44v6 possessed substantially enhanced EGFR, AKT, and MAPK phosphorylation; however, Met activity was reduced. No changes were seen in the level of total proteins expressed. These data suggested that CD44v6 may promote an aggressive, endocrine-desensitized phenotype in MCF-7 cells through the activation of the EGFR pathway. To explore this hypothesis, we investigated the sensitivity of CD44v6-overexpressing MCF-7 cells (MCF-7-CD44v6) to the EGFR inhibitor, gefitinib, with respect to their invasive capacity. Gefitinib inhibited the invasive nature of MCF-7-CD44v6 cells (Figure 7B) and reduced the endogenous activity of EGFR pathway components without affecting total levels of these proteins (Figure 7C).

\section{Specific Inhibition of CD44v6 in Endocrine-Resistant Cell Models is Associated with a Reduction in Their Invasive Capacity}

Having observed a differential contribution to the aggressive phenotype of MCF-7 cells between CD44v3 and CD44v6 

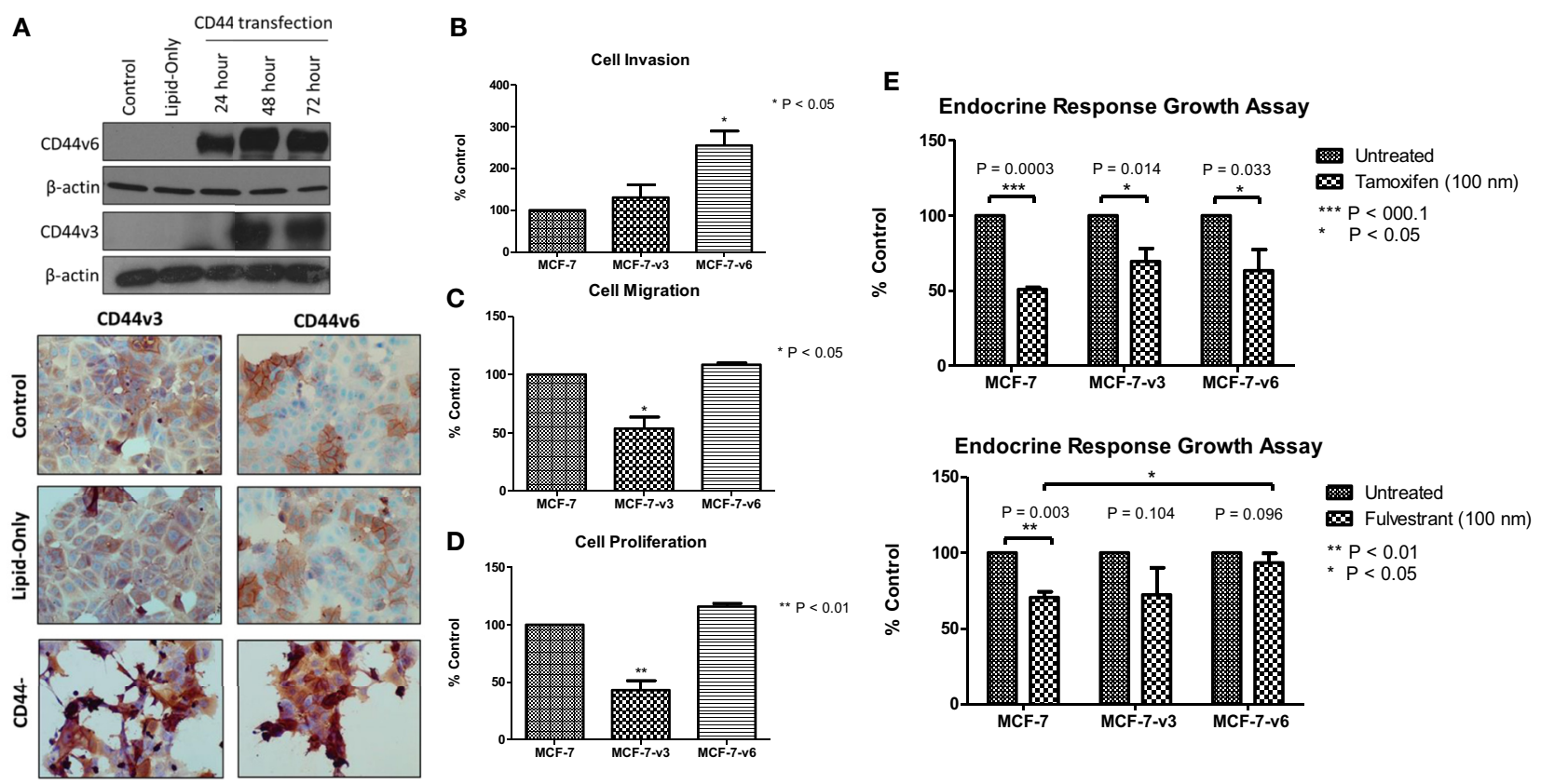

FIGURE 6 | Overexpression of CD44v6, but not CD44v3, in MCF-7 cells promotes an invasive phenotype. (A) Transfection of MCF-7 cells with CD44v3 or CD44v6 resulted in expression of these proteins to a similar extent as seen in the Tam-R and Fas-R cells but did not alter the expression of other CD44 variants. (B) Overexpression of CD44v6 resulted in a gain of invasive capacity in MCF-7 cells, in contrast to CD44v3 overexpression that reduced the migratory (C) and proliferative (D) capacity of these cells. MCF-7 cells overexpressing CD44 isoforms were exposed to tamoxifen or fulvestrant for 7 days and their growth determined by cell counting. (E) CD44v6-overexpressing MCF-7 cells exhibited a reduced response to fulvestrant, but not tamoxifen, compared to the control or CD44v3overexpressing cells.

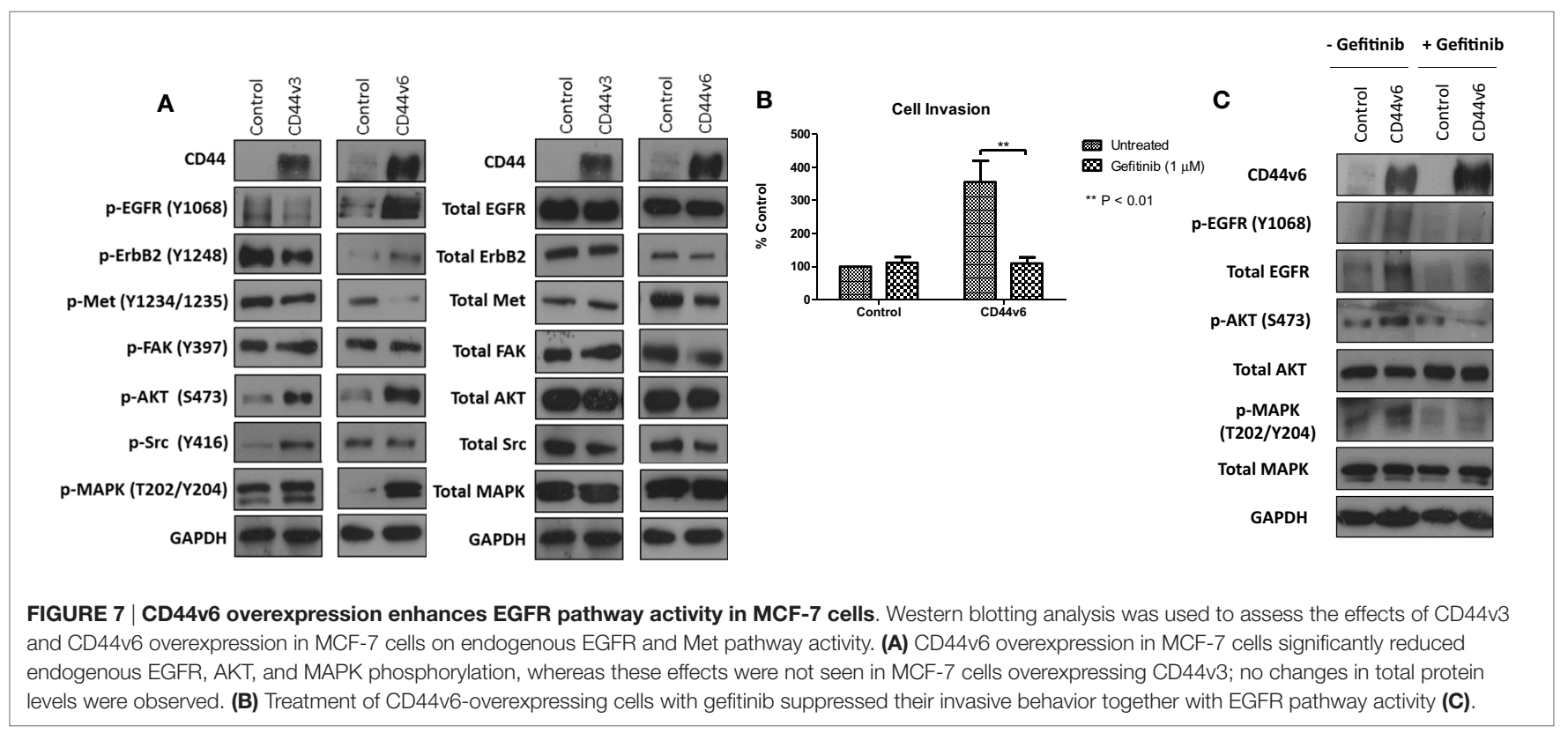

overexpression, we extended our studies into the resistant models in which we specifically inhibited CD44v6 expression, using siRNA, to explore the hypothesis that CD44v6 plays a key role in the aggressive phenotype of endocrine resistance. Western blotting revealed that CD44v6 siRNA was specific for this isoform in
Tam-R and Fas-R cells (Figures 8A,B). CD44v6 siRNA reduced the endogenous invasive and proliferative capacity of Tam- $\mathrm{R}$ but not Fas-R cells (Figures 8C,D). An increase in cellular migration was seen in Tam-R cells following loss of CD44v6 (Figures 8E). Accompanying this was a reduction in EGFR pathway components 


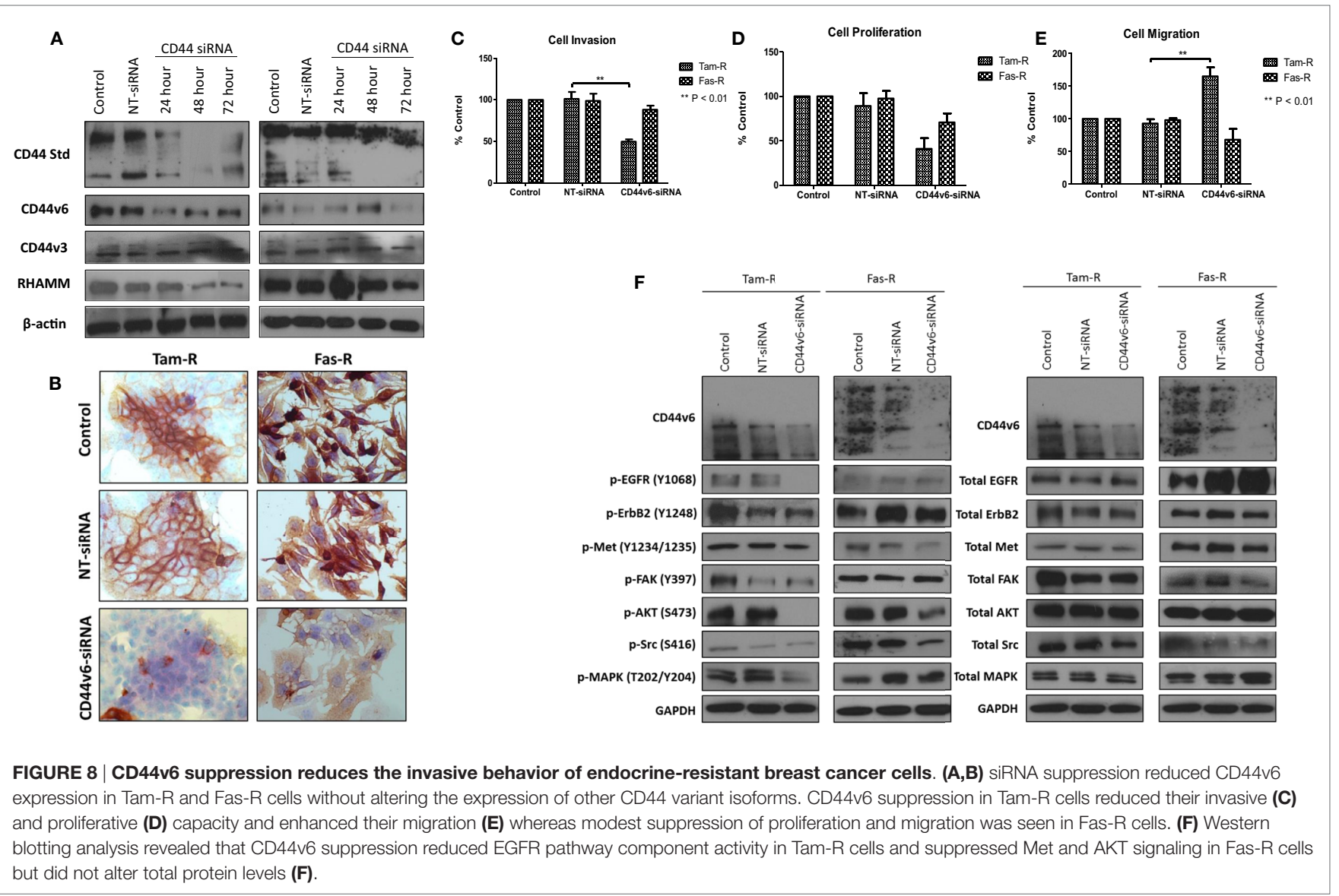

in Tam-R cells and suppressed Met and AKT signaling in Fas- $\mathrm{R}$ cells, however, total protein levels were unaffected (Figure $\mathbf{8 F}$ ).

\section{CD44v6 and EGFR Co-Expression Is Associated with a Worsened Outcome in Breast Cancer Patients}

In light of our in vitro evidence that CD44v6 represented a potential contributory factor to the aggressive phenotype of endocrineresistant cells through its ability to modulate EGFR signaling, we explored this hypothesis further in a small exploratory series of formalin-fixed paraffin-embedded TMAs representing 140 patients with ER+ primary breast cancers receiving adjuvant tamoxifen with a 20-year follow-up and for which the EGFR status was already known (30). X-tile was used to define optimal CD44v6 membrane cut point ( $H$-score of 47 ) versus patient outcome and statistical testing was performed using Log Rank (Mantel-Cox). Of the 140 TMA's studied in this series, 20 were negative for CD44v6 membrane expression. After the cutpoint was applied, 71/140 showed TMAs where CD44v6 staining was greater than the $H$-score cutpoint (Figure 9A). Interestingly, tumors highly positive for CD44v6 but having reduced or absent EGFR appeared to be associated with the most favorable DFI; the impact of co-expression of the EGFR in the CD44v6 cohort was to significantly reduce patient DFI (Figure 9B);
Mean survival $($ months \pm SD) $=141.9 \pm 7.3[$ CD44v6+/EGFR- $]$ versus $105.6 \pm 23.4(\mathrm{CD} 44 \mathrm{v} 6+/ \mathrm{EGFR}+), p<0.05$. A similar observation was apparent for tumors expressing EGFR in the context of reduced/absent CD44v6 where co-expression resulted in a significantly less favorable DFI than EGFR alone; Mean survival (months $\pm \mathrm{SD})=130.0 \pm 23.4$ [EGFR+/CD44v6-] versus $105.6 \pm 23.4$ [EGFR+/CD44v6+], $p<0.05$. Tumors with co-expression of CD44v6 and EGFR had a similar DFI to those absent for both markers. Cox regression $(\mathrm{C})$ revealed that tumors with a CD44v6+/EGFR+ phenotype were more associated with a poorer outcome versus grade although this was not significant.

\section{DISCUSSION}

Although current endocrine treatments for ER+ breast cancers work well, the phenomenon of acquired resistance still represents a major limiting factor in their overall effectiveness and resistant disease frequently occurs at distant sites with associated poor prognosis. Since acquisition of endocrine resistance is accompanied by a gain in aggressive cellular features that may drive distant spread, an understanding of the molecular mechanisms that contribute to this behavior may reveal novel therapeutic targets through which breast cancer outcome can be improved. We have previously shown that the standard form of the cell surface adhesion receptor, CD44, is overexpressed in Tam-R MCF-7 cells. 


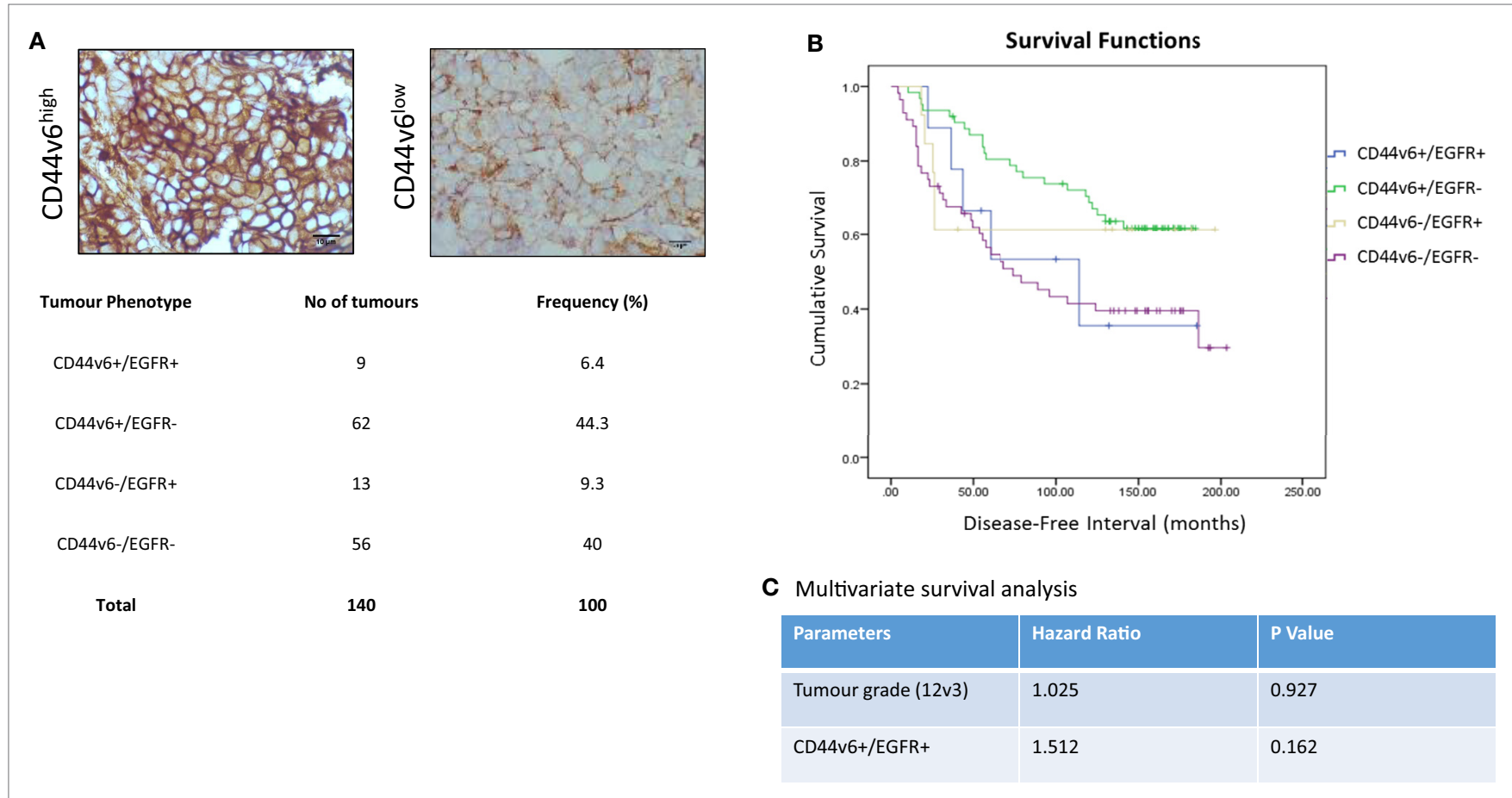

FIGURE 9 | CD44v6 and EGFR co-expression reduces DFI in tamoxifen-treated ER+ breast cancers. CD44v6 expression was determined in a TMA series ( $n=140$ ) of ER+ breast cancer patients that had received tamoxifen and for whom their EGFR status was known. (A) Representative images of high (H-score $>47)$ and low (H-score <47) CD44v6 staining in TMAs and the associated frequency of the four possible phenotypes encountered in this TMA series. (B) Kaplan-Meier survival plots for the four possible phenotypes demonstrating that co-expression of CD44v6 and EGFR (or lack of both) were associated with the poorest DFI. (C) Cox regression analysis suggested the CD44v6+/EGFR+ phenotype to be more associated with poorer outcome versus grade although this was not significant.

Here, we have extended these investigations to a further model of acquired fulvestrant resistance and also demonstrate the importance of the CD44v6 isoform as a mediator of their invasive phenotype and growth factor (EGFR) signaling in these models.

Our initial investigations revealed that, along with CD44, RHAMM was upregulated in acquired endocrine resistance. Interestingly, while suppression of CD44 by siRNA led to a corresponding reduction in RHAMM in both Tam-R and Fas-R cells, the converse was not seen, i.e., that modulation of RHAMM by siRNA did not affect CD44 expression. Moreover, RHAMM suppression did not affect the invasive, migratory, or proliferative nature of these cells. Taken together, this suggests that the aggressive phenotype in our resistant cell models is not dependent upon RHAMM. Subsequently, we investigated the CD44v3 and v6 isoforms of CD44 given their association with the cancer cell phenotype.

CD44v6 is suggested to represent an important prognostic marker for some cancer types where its elevated expression is associated with metastasis $(14,18)$. The association between CD44v6 and disease progression may stem from its ability to augment the activity of growth factor signaling pathways. In our study, we investigated changes in the expression and activity of a number of receptor tyrosine kinases known to be linked to an invasive phenotype. Of these, we observed that CD44v6 expression was associated with increased EGFR activity in addition to AKT and MAPK signaling, whereas Met activity was suppressed.
Interestingly, Yu et al. (17) found a strong correlation between CD44v6 and AKT expression that was associated with a shorter DFS across 98 samples of breast cancer tissues. Furthermore, AKT activity is reported to be elevated in CD44v6-overexpressing tumors (31), while CD44v6 is able to activate MAPK signaling in combination with other growth factor receptors $(32,33)$. Our data suggest that CD44v6 expression in some way activates EGFR signaling; we tested this hypothesis by challenging CD44v6+ cells with the EGFR inhibitor, gefitinib. Subsequently, our data showed that gefitinib was able to suppress the invasive capacity of these cells to that of the control levels (Figure $7 \mathbf{B}$ ) and also prevented the increase in EGFR, AKT, and MAPK observed following CD44v6 overexpression (7C). Given the literature supporting CD44 interactions with other RTKs, there is the possibility that CD44v6 may interact with other receptors in our cell models promoting downstream signaling and an invasive response. However, our data do suggest that irrespective of this, the EGFR represents a dominant pathway given the ability of EGFR pathway inhibition to circumvent CD44v6 effects. Similar findings have been reported by others where interactions between CD44 and erbB members increase cell motility (34-36) while our data additionally point to the co-expression of EGFR and CD44v6 as a clinically relevant phenomenon albeit in a small cohort of patients (Figure 9). Although our Cox regression analysis failed to demonstrate further significance of the CD44v6/EGFR phenotype, this is likely due to the low numbers $(n=9)$ in this subset 
and further investigation of CD44v6 \pm EGFR in a larger number may well reveal a more clearer association with outcome.

Importantly, our data allude to the potential role for CD44v6 in chemoresistance where its overexpression limits cellular response of ER+ endocrine-sensitive cells to fulvestrant. Recent reports have suggested a role between CD44v6 and chemoresistance in prostate cancer which may involve AKT pathway activation (31). Furthermore, a function of CD44v6 as a cell cycle regulator has been suggested potentially through its ability to modulate the Hippo effector, YAP, known to indirectly regulate cell cycle progression (37). Studies that have used combination treatments to suppress cell growth through cell cycle inhibition show that CD44v6 is also reduced in response to these treatments (38). These observations may explain to some degree our observations that CD44v6-overexpressing MCF-7 cells fail to respond to fulvestrant, with CD44v6 providing an indirect, positive input into cell cycle in the presence of fulvestrant. Given the interplay between CD44 and RTKs and the well-established cross talk between RTKs and the ER, it may further be that CD44 upregulation can indirectly activate or modulate the expression of the ER thereby limiting the sensitivity to endocrine agents. While an interesting hypothesis, this did not appear to be the case here as no change in ER expression or activity was seen in MCF-7 or Tam-R cells following CD44 manipulation; Fas-R cells are ER- (39) and no ER restoration was observed following CD44-siRNA (Bellerby, unpublished observations).

While our data suggest an important role for CD44v6 in the aggressive behavior of our endocrine-resistant cells, it is important to note a global knockdown of CD44 expression in both resistant cell models results in differential effects: while Tam-R cells lose their proliferative, invasive, and migratory capacity, only the invasive behavior is affected in Fas-R cells. One explanation for this may be the differential expression of growth factor receptors that accompany different forms of acquired resistance and, thus, provide different interacting partners for the CD44 isoforms. However, that CD44 can be suppressed to attenuate aggressive behavior irrespective of the resistant background suggests that its targeting may be of value.

Whilst CD44 overexpression is widely reported in a number of different tumor types where it correlates with advanced stage/ higher grade, such studies invariably use experimental approaches that are unable to differentiate between individual CD44 isoforms, masking the true pattern of CD44 isoform expression. Indeed the fact that some studies suggest a relationship between expression of CD44 standard or its variant isoforms with respect to prognosis (40-42), while other reports are less clear as to a relationship between CD44 and outcome (43-46) is likely due to the complexities of the CD44 expression pattern and the ability to clearly differentiate between different isoforms; our data further point to the importance of understanding the complexities of CD44 variant expression rather than CD44 per se in breast cancer. Recent

\section{REFERENCES}

1. Harvey JM, Clark GM, Osborne CK, Allred DC. Estrogen receptor status by immunohistochemistry is superior to the ligand-binding assay for predicting studies have demonstrated the importance of this, showing that a combination of CD44v6 and CD44s, but not CD44 alone, is able to predict survival in lung cancer patients (47), while pancreatic tumors with a "CD44v6+/CD44-" profile are more metastatic (41). Not only will understanding the contribution of specific CD44 isoforms to tumor progression/suppression be beneficial in developing prognostic markers but it may also reveal specific variants that may have therapeutic potential.

The v6 variant of the CD44 family is known to be highly expressed in invasive breast cancers (48) and has itself been the subject of investigation with respect to its therapeutic potential. While in recent years, these approaches have been met with some success in multiple carcinomas, including pancreatic (49), colon (50), and prostate (51) their effectiveness in breast cancer remains limited. However, the identification of CD44 as a marker of breast cancer stem cells has led to the development of a novel strategy through which to target CD44 and, thus, the subpopulation of stem-like cells that may reside in such tumors (52). Recently, the ability to exploit CD44 as a drug-delivery system in cancers, including breast has been investigated with encouraging results (53-55). Thus, the ability to identify specific CD44 isoforms that contribute to the progression of breast cancers offers a potential prognostic and therapeutic target in such tumors. Our data support the role of CD44v6 in breast cancer, particularly in the context of relapsed disease and suggest that therapeutically targeting this isoform may be of benefit in such contexts.

\section{AUTHOR CONTRIBUTIONS}

$\mathrm{RB}$ conceived and performed experimental analysis, data interpretation, manuscript preparation, and review. CS performed experimental analysis and data interpretation. SK undertook immunohistochemical staining of tissue and cell sections. JG undertook critical analysis of microarray data and clinical material data. UG undertook data evaluation and critical review of manuscript. AG undertook statistical analysis and critical review of manuscript. ER undertook review of clinical data and critical review of manuscript. PB-L undertook critical review of manuscript, scientific input, and project direction. SH conceived the project, supervised experimental work, assisted in data interpretation, manuscript preparation, review, and editing.

\section{ACKNOWLEDGMENTS}

The authors are grateful for the assistance of Lynne Farrow for microarray data analysis.

\section{FUNDING}

RB was funded by the In The Pink charity. response to adjuvant endocrine therapy in breast cancer. J Clin Oncol (1999) 17:1474-81.

2. Chia SK, Wolff AC. With maturity comes confidence: EBCTCG tamoxifen update. Lancet (2011) 378:747-9. doi:10.1016/S0140-6736(11)61128-8 
3. Osborne CK, Schiff R. Growth factor receptor cross-talk with estrogen receptor as a mechanism for tamoxifen resistance in breast cancer. Breast (2003) 12:362-7. doi:10.1016/S0960-9776(03)80003-6

4. Hiscox S, Morgan L, Barrow D, Dutkowskil C, Wakeling A, Nicholson RI. Tamoxifen resistance in breast cancer cells is accompanied by an enhanced motile and invasive phenotype: inhibition by gefitinib ('Iressa', ZD1839). Clin Exp Metastasis (2004) 21:201-12. doi:10.1023/B:CLIN.0000037697. 76011.1d

5. Khajah MA, Al Saleh S, Mathew PM, Luqmani YA. Differential effect of growth factors on invasion and proliferation of endocrine resistant breast cancer cells. PLoS One (2012) 7:e41847. doi:10.1371/journal.pone.0041847

6. Nguyen VT, Barozzi I, Faronato M, Lombardo Y, Steel JH, Patel N, et al. Differential epigenetic reprogramming in response to specific endocrine therapies promotes cholesterol biosynthesis and cellular invasion. Nat Commun (2015) 6:10044. doi:10.1038/ncomms10044

7. Hiscox S, Jordan NJ, Jiang W, Harper M, Mcclelland R, Smith C, et al. Chronic exposure to fulvestrant promotes overexpression of the c-Met receptor in breast cancer cells: implications for tumour-stroma interactions. Endocr Relat Cancer (2006) 13:1085-99. doi:10.1677/erc.1.01270

8. Olsson E, Honeth G, Bendahl PO, Saal LH, Gruvberger-Saal S, Ringner M, et al. CD44 isoforms are heterogeneously expressed in breast cancer and correlate with tumor subtypes and cancer stem cell markers. BMC Cancer (2011) 11:418. doi:10.1186/1471-2407-11-418

9. Banky B, Raso-Barnett L, Barbai T, Timar J, Becsagh P, Raso E. Characteristics of CD44 alternative splice pattern in the course of human colorectal adenocarcinoma progression. Mol Cancer (2012) 11:83. doi:10.1186/1476-4598-11-83

10. Wang SJ, Wreesmann VB, Bourguignon LY.Association of CD44 V3-containing isoforms with tumor cell growth, migration, matrix metalloproteinase expression, and lymph node metastasis in head and neck cancer. Head Neck (2007) 29:550-8. doi:10.1002/hed.20544

11. Bourguignon LY, Wong G, Earle C, Chen L. Hyaluronan-CD44v3 interaction with Oct4-Sox2-Nanog promotes miR-302 expression leading to self-renewal, clonal formation, and cisplatin resistance in cancer stem cells from head and neck squamous cell carcinoma. J Biol Chem (2012) 287:32800-24. doi:10.1074/ jbc.M111.308528

12. Todaro M, Gaggianesi M, Catalano V, Benfante A, Iovino F, Biffoni M, et al. $\mathrm{CD} 44 \mathrm{v} 6$ is a marker of constitutive and reprogrammed cancer stem cells driving colon cancer metastasis. Cell Stem Cell (2014) 14:342-56. doi:10.1016/j. stem.2014.01.009

13. Bar JK, Zub L, Lis-Nawara A, Noga L, Jelen M, Paradowski B. Expression and interactions between cell adhesion molecules CD44v6 and E-cadherin in human gliomas. Adv Clin Exp Med (2014) 23:827-34. doi:10.17219/ acem $/ 37261$

14. Shi J, Zhou Z, Di W, Li N. Correlation of CD44v6 expression with ovarian cancer progression and recurrence. BMC Cancer (2013) 13:182. doi:10.1186/1471-2407-13-182

15. Zhou ZJ, Dai Z, Zhou SL, Fu XT, Zhao YM, Shi YH, et al. Overexpression of HnRNP Al promotes tumor invasion through regulating CD44v6 and indicates poor prognosis for hepatocellular carcinoma. Int J Cancer (2013) 132:1080-9. doi:10.1002/ijc.27742

16. Lian ZQ, Yang MT, Hou JH, Luo RZ, Wang X, Tang J. [Expression and clinical significance of adhesive molecule CD44v6 in breast invasive ductal carcinoma]. Ai Zheng (2006) 25:1291-5.

17. Yu P, Zhou L, Ke W, Li K. Clinical significance of pAKT and CD44v6 overexpression with breast cancer. J Cancer Res Clin Oncol (2010) 136:1283-92. doi:10.1007/s00432-010-0779-x

18. Saito $\mathrm{S}$, Okabe $\mathrm{H}$, Watanabe $M$, Ishimoto $T$, Iwatsuki $M$, Baba $Y$, et al. CD44v6 expression is related to mesenchymal phenotype and poor prognosis in patients with colorectal cancer. Oncol Rep (2013) 29:1570-8. doi:10.3892/ or.2013.2273

19. Hao J, Chen H, Madigan MC, Cozzi PJ, Beretov J, Xiao W, et al. Co-expression of CD147 (EMMPRIN), CD44v3-10, MDR1 and monocarboxylate transporters is associated with prostate cancer drug resistance and progression. $\mathrm{Br}$ J Cancer (2010) 103:1008-18. doi:10.1038/sj.bjc.6605839

20. Wang L, Li HG, Wen JM, Peng TS, Zeng H, Wang LY. Expression of CD44v3, erythropoietin and VEGF-C in gastric adenocarcinomas: correlations with clinicopathological features. Tumori (2014) 100:321-7. doi:10.1700/ 1578.17216
21. Gee JM, Eloranta JJ, Ibbitt JC, Robertson JF, Ellis IO, Williams T, et al. Overexpression of TFAP2C in invasive breast cancer correlates with a poorer response to anti-hormone therapy and reduced patient survival. JPathol (2009) 217:32-41. doi:10.1002/path.2430

22. Abd El-Rehim DM, Pinder SE, Paish CE, Bell J, Blamey RW, Robertson JF, et al. Expression of luminal and basal cytokeratins in human breast carcinoma. J Pathol (2004) 203:661-71. doi:10.1002/path.1559

23. Hiscox S, Baruha B, Smith C, Bellerby R, Goddard L, Jordan N, et al. Overexpression of CD44 accompanies acquired tamoxifen resistance in MCF7 cells and augments their sensitivity to the stromal factors, heregulin and hyaluronan. BMC Cancer (2012) 12:458. doi:10.1186/1471-2407-12-458

24. Massarweh S, Osborne CK, Creighton CJ, Qin L, Tsimelzon A, Huang S, et al. Tamoxifen resistance in breast tumors is driven by growth factor receptor signaling with repression of classic estrogen receptor genomic function. Cancer Res (2008) 68:826-33. doi:10.1158/0008-5472.CAN-07-2707

25. Bourguignon LY, Singleton PA, Zhu H, Zhou B. Hyaluronan promotes signaling interaction between CD44 and the transforming growth factor beta receptor I in metastatic breast tumor cells. J Biol Chem (2002) 277:39703-12. doi:10.1074/jbc.M204320200

26. Wang SJ, Bourguignon LY. Hyaluronan and the interaction between CD44 and epidermal growth factor receptor in oncogenic signaling and chemotherapy resistance in head and neck cancer. Arch Otolaryngol Head Neck Surg (2006) 132:771-8. doi:10.1001/archotol.132.7.771

27. Bao W, Fu HJ, Xie QS, Wang L, Zhang R, Guo ZY, et al. HER2 interacts with CD44 to up-regulate CXCR4 via epigenetic silencing of microRNA-139 in gastric cancer cells. Gastroenterology (2011) 141(2076-2087):e2076. doi:10.1053/j.gastro.2011.08.050

28. Maxwell CA, Benitez J, Gomez-Baldo L, Osorio A, Bonifaci N, FernandezRamires R, et al. Interplay between BRCA1 and RHAMM regulates epithelial apicobasal polarization and may influence risk of breast cancer. PLoS Biol (2011) 9:e1001199. doi:10.1371/journal.pbio.1001199

29. Lugli A, Zlobec I, Gunthert U, Minoo P, Baker K, Tornillo L, et al. Overexpression of the receptor for hyaluronic acid mediated motility is an independent adverse prognostic factor in colorectal cancer. Mod Pathol (2006) 19:1302-9. doi:10.1038/modpathol.3800648

30. Abd El-Rehim DM, Pinder SE, Paish CE, Bell JA, Rampaul RS, Blamey RW, et al. Expression and co-expression of the members of the epidermal growth factor receptor (EGFR) family in invasive breast carcinoma. Br J Can (2004) 91:1532-42. doi:10.1038/sj.bjc.6602184

31. Ni J, Cozzi PJ, Hao JL, Beretov J, Chang L, Duan W, et al. CD44 variant 6 is associated with prostate cancer metastasis and chemo-/radioresistance. Prostate (2014) 74:602-17. doi:10.1002/pros.22775

32. Jung T, Gross W, Zoller M. CD44v6 coordinates tumor matrix-triggered motility and apoptosis resistance. J Biol Chem (2011) 286:15862-74. doi:10.1074/ jbc.M110.208421

33. Singh R, Subramanian S, Rhodes JM, Campbell BJ. Peanut lectin stimulates proliferation of colon cancer cells by interaction with glycosylated CD44v6 isoforms and consequential activation of c-Met and MAPK: functional implications for disease-associated glycosylation changes. Glycobiology (2006) 16:594-601. doi:10.1093/glycob/cwj108

34. Kim Y, Lee YS, Choe J, Lee H, Kim YM, Jeoung D. CD44-epidermal growth factor receptor interaction mediates hyaluronic acid-promoted cell motility by activating protein kinase $\mathrm{C}$ signaling involving Akt, Rac1, Phox, reactive oxygen species, focal adhesion kinase, and MMP-2. J Biol Chem (2008) 283:22513-28. doi:10.1074/jbc.M708319200

35. Palyi-Krekk Z, Barok M, Kovacs T, Saya H, Nagano O, Szollosi J, et al. EGFR and ErbB2 are functionally coupled to CD44 and regulate shedding, internalization and motogenic effect of CD44. Cancer Lett (2008) 263:231-42. doi:10.1016/j.canlet.2008.01.014

36. Cho SH, Park YS, Kim HJ, Kim CH, Lim SW, Huh JW, et al. CD44 enhances the epithelial-mesenchymal transition in association with colon cancer invasion. Int J Oncol (2012) 41:211-8. doi:10.3892/ijo.2012.1453

37. Zhang $\mathrm{Y}, \mathrm{Xia} \mathrm{H}, \mathrm{Ge} \mathrm{X}$, Chen Q, Yuan D, Chen Q, et al. CD44 acts through RhoA to regulate YAP signaling. Cell Signal (2014) 26:2504-13. doi:10.1016/j. cellsig.2014.07.031

38. Ji F, Ma D, Liu Z, Xie X. Rosiglitazone amplifies the sensitivity of docetaxel and reduces the expression of CD44v6. Oncol Lett (2014) 7:1284-8. doi:10.3892/ ol.2014.1824 
39. Mcclelland RA, Barrow D, Madden TA, Dutkowski CM, Pamment J, Knowlden JM, et al. Enhanced epidermal growth factor receptor signaling in MCF7 breast cancer cells after long-term culture in the presence of the pure antiestrogen ICI 182,780 (Faslodex). Endocrinology (2001) 142:2776-88. doi:10.1210/en.142.7.2776

40. Li X, Ma X, Chen L, Gu L, Zhang Y, Zhang F, et al. Prognostic value of CD44 expression in renal cell carcinoma: a systematic review and meta-analysis. Sci Rep (2015) 5:13157. doi:10.1038/srep13157

41. Li XP, Zhang XW, Zheng LZ, Guo WJ. Expression of CD44 in pancreatic cancer and its significance. Int J Clin Exp Pathol (2015) 8:6724-31.

42. Wu Y, Li Z, Zhang C, Yu K, Teng Z, Zheng G, et al. CD44 family proteins in gastric cancer: a meta-analysis and narrative review. Int J Clin Exp Med (2015) 8:3595-606.

43. Morrin M, Delaney PV. CD44v6 is not relevant in colorectal tumour progression. Int J Colorectal Dis (2002) 17:30-6. doi:10.1007/s003840100335

44. Horn LC, Raptis G, Fischer U, Hentschel B, Kohler U, Richter CE, et al. CD44-v6 concentrations in carcinoma of the uterine cervix: lack of prognostic significance. Arch Gynecol Obstet (2005) 273:104-6. doi:10.1007/ s00404-005-0039-5

45. Taran K, Kobos J, Sitkiewicz A, Sporny S. Estimation of prognostic value of CD44 expression in neuroblastic tumours in children. Folia Neuropathol (2007) 45:126-32.

46. Saleh F, Reno W. Invasive cribriform breast carcinomas in patients with grade 1 and stage IIA (T2 N0 M0) breast cancer strongly express the v3 and v6, but not the $\mathrm{v} 4$ isoforms of the metastatic marker CD44. Neoplasma (2008) $55: 246-55$

47. Jiang H, Zhao W, Shao W. Prognostic value of CD44 and CD44v6 expression in patients with non-small cell lung cancer: meta-analysis. Tumour Biol (2014) 35:7383-9. doi:10.1007/s13277-014-2150-3

48. Vermeulen JF, Van Brussel AS, Van Der Groep P, Morsink FH, Bult P, Van Der Wall E, et al. Immunophenotyping invasive breast cancer: paving the road for molecular imaging. BMC Cancer (2012) 12:240. doi:10.1186/1471-2407-12-240

49. Qian C, Wang Y, Chen Y, Zeng L, Zhang Q, Shuai X, et al. Suppression of pancreatic tumor growth by targeted arsenic delivery with anti-CD44v6 single chain antibody conjugated nanoparticles. Biomaterials (2013) 34:6175-84. doi:10.1016/j.biomaterials.2013.04.056
50. Misra S, Hascall VC, De Giovanni C, Markwald RR, Ghatak S. Delivery of CD44 shRNA/nanoparticles within cancer cells: perturbation of hyaluronan/CD44v6 interactions and reduction in adenoma growth in Apc Min/+ MICE. JBiol Chem (2009) 284:12432-46. doi:10.1074/jbc.M806 772200

51. Liu C, Kelnar K, Liu B, Chen X, Calhoun-Davis T, Li H, et al. The microRNA miR-34a inhibits prostate cancer stem cells and metastasis by directly repressing CD44. Nat Med (2011) 17:211-5. doi:10.1038/ nm. 2284

52. Diessner J, Bruttel V, Stein RG, Horn E, Hausler SF, Dietl J, et al. Targeting of preexisting and induced breast cancer stem cells with trastuzumab and trastuzumab emtansine (T-DM1). Cell Death Dis (2014) 5:e1149. doi:10.1038/ cddis. 2014.115

53. Fan W, Wang X, Ding B, Cai H, Wang X, Fan Y, et al. Thioaptamerconjugated CD44-targeted delivery system for the treatment of breast cancer in vitro and in vivo. J Drug Target (2015):359-71. doi:10.3109/1061 186X.2015.1077850

54. Gener P, Gouveia LP, Sabat GR, De Sousa Rafael DF, Fort NB, Arranja A, et al. Fluorescent CSC models evidence that targeted nanomedicines improve treatment sensitivity of breast and colon cancer stem cells. Nanomedicine (2015) 11(8):1883-92. doi:10.1016/j.nano.2015.07.009

55. Yang C, He Y, Zhang H, Liu Y, Wang W, Du Y, et al. Selective killing of breast cancer cells expressing activated CD44 using CD44 ligand-coated nanoparticles in vitro and in vivo. Oncotarget (2015) 6:15283-96. doi:10.18632/ oncotarget. 3681

Conflict of Interest Statement: This research was conducted in the absence of any commercial or financial relationships that could be construed as a potential conflict of interest.

Copyright (c) 2016 Bellerby, Smith, Kyme, Gee, Günthert, Green, Rakha, Barrett-Lee and Hiscox. This is an open-access article distributed under the terms of the Creative Commons Attribution License (CC BY). The use, distribution or reproduction in other forums is permitted, provided the original author(s) or licensor are credited and that the original publication in this journal is cited, in accordance with accepted academic practice. No use, distribution or reproduction is permitted which does not comply with these terms. 